\title{
Translation and Literary Genres: A Case Study of Poetry in Bengali and Marathi
}

\section{Chandrani Chatterjee and Milind Malshe}

\begin{abstract}
The paper focuses on the relationship between genre and translation. It is significant to note how certain genres change character while passing from one culture to another. In such a process concepts like adaptation, assimilation and transformation become particularly important. In this paper, apart from some general considerations we have tried to trace the adaptation of the 'sonnet', essentially a European form, into Bengali and Marathi literature. The article perorates with the conclusion that the reception of the sonnet form in the Bangla and Marathi literary milieus has been quite different, the former assimilating it and the latter treating it as a passing phase.
\end{abstract}

The notion of translation as a cultural idea is perhaps best perceived in the translation of literary forms or genres. While generic features help one in identifying a particular work as an epic, a tragedy or a comedy, the instability of such terms is also an accepted fact. Genres cannot be essentialized; at best every genre can be said to have multiple distinguishing traits. The character of genres is that they change; the variation and

Translation Today Vol. 2 No. 2 Oct. 2005 @ CIIL 2005 
Modification of convention have historical and theoretical significance.

A study of such variation or modification of forms becomes particularly interesting when the exchange takes place across cultures - in what are called "cultural encounters". The influence, which European models had on Indian writers, has already been recognized. One of the most dominant features of Indian literature, both creative and critical, since the beginning of the colonial period, is a passionate search for modernity. This search was intensified with the increasing exposure to Western thought and literature, and finally culminated in the twentieth century. The ancient Indian literature had categories like i) pracina (old) and navina (new) and ii) marga (classical, traditional) and desi (local, folk), understood in terms of chronological order or the degree of stylization. But never was there a strong and conscious attempt to assert one's modernity and the other's non-modernity. In the Indian situation, modernity (adhunikata), as a category was not a development through phases as the Renaissance and Reformation, Enlightenment and Industrial Revolution. The idea of modernity emerged in Indian literature from the inner urge of the literary community to create alternatives to the literary models and canons dominating for centuries. Undoubtedly, this process took place under colonization and in the wake of the new British education. At the same time, there was also a desire of trying to understand one's own cultural ethos. However, so strongly propelled was the urge by the Indian exposure to Western models that modernity came to be viewed, particularly by the conservatives, as synonymous to Westernization. Not only were the European models being used by the Indian writers, but a lot of work was also being done in translation. 


\section{II}

A study of the history of translation reveals the ways in which original texts are rewritten and also exposes the routes through which innovations are introduced in the literary field. The colonial context of these works inscribes the asymmetrical relationship between the European originals and their Indian translations. The proliferation of texts translated from European languages, especially English, in colonial India indicates the multiple layers of contact between the two cultures. A Checklist of Translations of European Texts in Bengali, 1800-1900, prepared by the Department of English, Jadavpur University, reveals the copious work which was being done in translation around this time. Apart from literature, which is divided into fiction, poetry, drama and miscellaneous works, the checklist includes subjects like Bible translations, biographies and exemplary lives, economics, general science, geography, history, law, medicine and child rearing, philosophy, political tracts, religion and history of religion. The Checklist is also an indication of the blurring of generic boundaries that take place while translating across cultures. For example, Arabian Nights Entertainments is translated by Nilmani Basak as Arabya Upanyas (PartI, II and III). The term 'upanyas' in Bengali, refers to the generic category of the novel. Arabian Nights Entertainments, as we know, is a collection of stories written in Arabic which were made known in Europe by the translation of Antoine Galland (1646-1715). In calling his translation 'upanyas', Nilmani Basak, was raising in his readers a 'horizon of expectation' about the nature of the work. Robert Hans Jauss in his Toward an Aesthetic of Reception coined the phrase 'horizon of expectation'. According to Jauss, "A literary work, even when it appears to be new, does not present itself as something absolutely new in an informational vacuum, but predisposes its audience to a very specific kind of reception by announcements, overt and covert signals, familiar characteristics, or implicit allusions..." Significantly enough, Jauss also focuses on the concept of genre as an important way of arousing 'horizon of expectations'. The 
Checklist also includes other translations of the same work. Satyacharan Gupta, for example, calls his work Ekadhik Sahasra Rajani, a closer rendering of The Thousand and One Nights.

\section{III}

A study of some of the genres like the epic and the sonnet which were being appropriated by Indian writers reveals not only how genres change across cultures but also the fact that genres have a tendency to diffuse. Though generic formulations guide the process of creation and interpretation, their universality can be questioned. Since the act of translation is in itself a culture-specific endeavour, it is rewarding to ask how one reconciles the universality and culturespecificity of generic translation.

We may examine here the process of appropriation of the sonnet into Bengali literature. Like many other terms current in literary criticism and indispensable on account of consequent convenience, the word 'form' presents difficulties in the way of a strict and logical definition. It has different shades of meaning, and to use it in any exclusive sense will not be correct. Applied to poetry, 'form' may be interpreted as the metrical pattern or frame in which words are set, the words themselves or poetic diction; the division into stanzas; the division into rhymed and unrhymed or blank verse and others. In this light, we would analyze the Bengali sonnet tradition., defines a sonnet as "a poem consisting of 14 lines (of 11 syllables in Italian, generally 12 in French, and 10 in English), with rhymes arranged according to one or other of certain definite schemes, of which the Petrarchan and Elizabethan are the principal, viz.:1) $a b$ b a $a b b$, followed by two, or three, other rhymes in the remaining six lines, with a pause in the thought after the octave (not always observed by English imitators, of whom Milton and Wordsworth are prominent examples); 2) $a b a b c d c d e f e f g g$. The sonnets of Shakespeare are in the latter form." 
It is clear that there is a distinct possibility of breaking rules and the desire to experiment with the generic conventions. In fact, the doctrine of the purity of genres disappeared with the neoclassical theorists. Thus, though Derrida begins his essay 'The Law of Genre' by positing two statements "Genres are not to be mixed. I will not mix genres", the essay ends on a different note where, according to Derrida, the law of contamination is inherent in the generic law. This tendency of genres to diffuse and to be contaminated to create what may be called 'hybrid' genres is particularly noticeable in generic translations across cultures.

Of the many forms introduced into Bengali literature through the influence of the West, the sonnet has perhaps succeeded the most. Michael Madhusudan Dutta (1824-1873) was the first to introduce the sonnet into Bengali literature. In Michael Madhusudan Dutta's letter number thirty seven, addressed to his friend Raj Narayan Basu, the poet noted: 'I want to introduce the sonnet into our language...if cultivated by men of genius; our sonnet would in time rival the Italian.' Madhusudan Dutta published a collection of one hundred and two sonnets called Chaturdashpadi Kavitavali (1866), written during his stay in France. In the second poem of the anthology, the poet relates the brief history of the sonnet and its introduction into Bengali literature. Madhusudan Dutta wrote a sonnet in Bengali, tracing the history of a new genre which was being introduced into Indian poetry from European literature. He reminds the reader of the Italian poet Francesco Petrarch, who found this little gem in the mine of poetry and dedicated it to the temple of the Muse. The goddess accepted the gift and rewarded the poet graciously. In a similar fashion Michael Madhusudan Dutta himself wants to offer the gem, which he considers a suitable gift to Bharati in Bharat. The sonnet in the Bengali original runs as follows:

Italy, bikhyato desh, kabyer kanon,

Bohubidh pik jotha gaye modhusware,

Sangeet-sudhar ras kori borishon, 
Translation and Literary Genres: A Case Study of Poetry

in Bengali and Marathi

Basanto amod mon puri nirontore; -

Se deshe janom purbe korila grohon

Francesco Petrarca kavi; bakdevir bore

Boroi joshoshi sadhu, kavi-kul-dhon,

Rasana amrite sikto, swarna veena kore.

Kavyer khwanite peye ei khudro moni,

Swamandire prodanila banir chorone

Kavindra: prosannabhave grahilo janani

(mononito bor diya) e upokorone.

Bharate Bharati-pada upojukto goni,

Upaharswarupe aji aropi rotone.

My translation of the Bengali sonnet follows:

Italy, the famous country, is the garden of poetry,

Where various cuckoos sing melodiously,

Pouring the sudha rasa of music,

Which fills the heart with the ecstasy of Spring;-

In that land was born

The poet Francesco Petrarca; with the boon of goddess Saraswati

He was a famous person, the treasure of the poets,

He was immersed in the quest for aesthetic pleasures, with a golden veena in his hands.

Discovering this small gem in the mine of poetry,

Offered it to the goddess in his own temple

The King of poets: the Muse accepted it graciously

(Blessing him with desired boon) in a similar fashion.

Considering it a suitable gift for Bharati in Bharat,

I now offer it to the Goddess.

This particular sonnet is constructed on the Petrarchan model. The rhyme scheme is as follows a b a b c d c d e f e f e f. However, since Michael belonged to the mid-nineteenth century, he was also aware of the various forms popular in his time. Thus his anthology contains other rhyme schemes as well. The schemes which were part of theoretical constructions for Petrarch had become a 
historical phenomenon for Michael. The sonnet, a European form, appeared to Michael not as a genre fixed for all time, but as a changing one because of his historical location and familiarity with several European languages. Michael introduced the Petrarchan sonnet as well as the Shakespearean, and thus opened the possibility of the entry of other types. Finally there was a total dismantling of the structure and a mere adherence to the fourteen lines or seven couplets structure. Michael himself suggested such possibilities when he called his sonnets Chaturdashpadi Kavitavali (the fourteen line verse). The sonnet is thus assimilated into Bengali literature not only through the installation of the historical genres, but also through the actualization of other theoretical possibilities. So far as the rhyme scheme is concerned, Michael did not contribute anything original. However, he contributed a new dimension to his sonnets which refused to be confined to one particular thematic zone. It expressed a multitude of experiences. The third sonnet, for example, titled Bangobhasha, is a sort of lament, where the poet realizing the potentialities which his mother tongue has, condemns his going to an alien land and trying to write in English. The sonnet ends with the advice of the Muse and the poet's return to his own mother tongue. The rhyme scheme of this poem is also different from the earlier one. In this sonnet, the poet follows the following rhyme scheme: $\mathrm{a} b \mathrm{a} b$ $\mathrm{c} \mathrm{d} \mathrm{c} \mathrm{d} \mathrm{e} \mathrm{f} \mathrm{e} \mathrm{g} \mathrm{g.} \mathrm{It} \mathrm{is} \mathrm{more} \mathrm{like} \mathrm{the} \mathrm{Shakespearean} \mathrm{sonnet} \mathrm{with} \mathrm{a}$ concluding couplet.

It is important at this point to understand the process and the moment of appropriation of a particular genre. What the recipient culture considers worth imitating needs to be taken into consideration in this regard. In the case of Michael Madhusudan Dutta, the European form, the sonnet, provided not only a model but also the scope for innovation and experimentation, and thus is in a way an attempt to 'play' with the available genre. The analogy of 'play' needs to be further explained. The aesthetic theory of the European Enlightenment privileged 'play' over 'game' in its free and creative aspects, as an analogy, or even a synonym for art. In his 
Letters on the Aesthetic Education of Man, Schiller describes the 'play-drive' as mediating between the 'sense-drive' and the 'formdrive', and producing the realm of art. Art could thus be considered as a form of creative play, with the circumscribed limits of cultural traditions, standards, structures or rules, infinitely repeatable but with new variations each time it is played out. Returning to the question of genre per se, one could say that the regulatory and repetitive structures of genre are constantly disrupted by the anarchic tendencies of writing as 'play'. The writer plays with genre. When one considers the dynamics of genre creation, Michael Madhusudan Dutta's need to deviate from the precedent of the European models available, reveals a new awareness of form and textuality. Thus, the Bengali sonnet must be understood in terms both of similarity and difference when compared to the European practice.

Michael Madhusudan Dutta's sonnets prepared the way for other sonnet writers like Nabin Chandra Sen and Rabindranath Tagore. Nabin Chandra Sen made a curious attempt in the sonnet form, where the alternate lines were of the same length in the first twelve lines; while in a regular sonnet, the lines are of equal length. It would be worth quoting the sonnet of Nabin Chandra Sen:

\section{The Sonnet}

Tridiv jotsnya devi murti, dhori.

Aji ki bhutole khoshi?

Jotsyna sagore jotsnya dahlia

Shashi korotole udilo shashi

Pabitratoro? Ki je pabitrata,

Tridiv madhuri poriche jhori

Sudhngshu hoyte, sudha angshu jano,

Pappurno dhora pabitro kori.

Nidrante dekhinu kaksha andhakar

Alokiche murti - manabi noe.

Bhorila hridoy, bhahilo nayone- 
Anandoshru;chitto chandrikamoy.

Aloki baishakhi-jotsnya-nishi

Aloke alok gelo ki mishi!

There are four distinct elements to be considered in the sonnet - the length of each line, the rhyme scheme and the organization of thought implied by the same. In all but the last item there have been innovations, with a view of greater assimilation. In Rabindranath Tagore, there are many variations of the sonnet form. There are seven couplets, each containing a different rhyme scheme as in Vairagya or Devatar Viday (Chaitali); there are two quatrains followed by three couplets as in Punyer-hisab in the same book; there is again, one quatrain followed by five couplets a in his Didi. Naivedya contains as many as seventy seven sonnets, all consisting of seven couplets. However, in the collection titled Smaran, there are many fourteen line poems where each line consists of eighteen syllables and not fourteen, the latter being the convention. In Utsarga the two varieties are used side by side, both of seven couplets, but some contain fourteen syllables in each line while in others the number of syllables is eighteen. In his Gitanjali, there are many poems of fourteen lines but the rhyme scheme is different.

Jibanananda Das, perhaps the greatest Bengali poet after Rabindranath Tagore was also a practitioner of the sonnet. Jibanananda Das' anthology entitled, Rupashi Bangla contain many such sonnets. It is said that, during the Liberation War of Bangladesh, Bengali fighters kept Rupashi Bangla in their camps and read the poems as a source of inspiration.

Shakti Chattopaddhay (1933-1995) was immensely influenced by the poetic style of Jibanananda Das. Chattopaddhay also composed some poems in the sonnet tradition. In the sphere of modern Bengali poetry, the name of Joy Goswami cannot go unnoticed. He began composing at an early age and his first published collection of poems was entitled 'Christmas $O$ Sheeter 
Sonnet Guccha' (lit. 'A Collection of Christmas and Winter Sonnets')

All these examples show that the sonnet form has been thoroughly assimilated into Bengali literature, with changes, additions and alterations which the writers of a different culture thought suitable. The Bengali sonnet, far from being a mere pastiche of the European model added new elements unknown of before and thus added a new dimension to the world sonnet tradition.

\section{IV}

In Marathi literature V.M.Mahajani translated some of Shakespeare's sonnets in Kavyakusumanjali (1885). However, the real foundations were laid by the poet Keshavsut (1866-1905) and the lyricist Tambe (1873-1941). Keshavsut called the form chaturdashaka. He contributed both independent poems and translations to Marathi literature although his independent poems were more successful. His first 'chaturdashaka' was published in 1892 and was titled 'Mayurasan ani Tajmahal'. Some of his other 'chaturdashakas' include 'Amhi kon' (translated literally as "Who are we?"), 'Pratibha' (lit. Imagination), 'Priti ani Tu' (lit.'Love and You'), 'Chiraviyuktache udgar' (lit.'Exclamation from a permanently separated person') Keshavsut experimented both in the Shakespearean and Miltonic tradition. 'Shradulavikridita vritta' (a particular combination of short and long syllables), was naturalized by Keshavsut as the conventional form of sonnet writing. However, it is noteworthy, that none of the Marathi poets accepted the Western rigidity of rhyme scheme while writing their sonnets. Thus, it was not a mere pastiche of the European models. The genre was being appropriated to suit the requirements of both the readers and the writers. 
The major flourish in Marathi sonnet tradition came with a group of writers called 'Ravikiran-mandal' (founded in 1923 and the poets of this group were influential during the 1920s and 1930s). This group prolifically produced sonnets on various themes. They also experimented with the sonnet sequence. Madhav Julian's 'Tutalele Duve' (lit.'Broken Links'), and Kavi Yashvant's 'Bhava Taranga' (lit.'Ripples of Emotions'), were sonnet sequences produced by 'Ravikiran-mandal'. The endeavours of the Ravikiranmandal ignited several controversies and debates regarding the form in which the poets of this group were trying their hands. Controversies also centered around what this genre should be called in Marathi. Alternatives like 'chaturdashpadi geetika' and 'swanitaka' were suggested. Finally, however, S.B.Ranade and Madhav Julian of Ravikiran-mandal zeroed in on suneet, which has been widely accepted ever since (one cannot miss the echo of the English 'sonnet').

A parody of the sonnet tradition was taken up by the poet Keshavkumar (Acharya Atre). He wrote parodies, some of which were sonnets in an anthology called Zenduchi Phule (first published in 1925; in 1972, S.G.Malshe edited the eighth edition with a long introduction). In order to de-romanticize and debunk the imitative tradition of the Ravikiran-mandal, he deliberately called his form 'sutaka' (observation of the post-funeral Hindu rites) instead of calling it 'suneet'. Parodying the hue and cry raised over the appropriate name for the form in literary circles, Keshavkumar imagines a 'Zendu Pustak Pharmacy' which prefers 'sutaka' to 'suneet'. The emptiness of the discussions and of over-enthusiasm of some of the experiments pertaining to the genre was aptly satirized by Keshav kumar.

Since then there has not been enough experimentation with this form in Marathi literature. However, in the 1960s Vinda Karandikar wrote what he called 'mukta suneete' (lit. free sonnets). These poems varied between thirteen and fifteen lines, without any 
consistent prosody. It was a combination of the 'mukta chanda' (free verse) with the precision of fourteen lines or so. Thus, the situation in Marathi is that the sonnet form has not really been assimilated into the tradition.

\section{V}

A comparative look at the reception of the 'sonnet' form in Bengali and Marathi literature reveals that genres change character while passing from one culture to another. This can perhaps be analyzed with the help of the Jaussian concept of 'horizon of expectations'. For Jauss, the concept of genre is an important way of "founding and altering" the "horizon of expectations": "The analysis of the literary experience of the reader avoids the threatening pitfalls of psychology if it describes the reception and the influence of a work within the objectifiable system of expectations that arises for each work in the historical moment of its appearance, from a preunderstanding of the genre, and from the opposition between poetic and practical language."

The above case study of Bengali and Marathi literature reveals such a process at work. It appears that the Marathi readers treated the sonnet as an alien form. On the contrary, the Bengali readers appear to be more receptive. The varying degree of reception of the same European form, in two major Indian languages can perhaps be explained as follows: while, the European form has been completely assimilated into Bengali literature, it remained only a passing phase in Marathi literature. 


\section{REFERENCES}

Dutta, Michael Madhusudan (1999) Letters in Madhusudan Rachanavali. Calcutta: Sahitya Samsad. pp 497-592

Dutta, Michael Madhusudan (1999) Madhusudan Rachanavali. Calcutta: Sahitya Samsad

Jauss, Hans Robert (1982) Toward an Aesthetic of Reception. (Tran.) Timothy Bahti. Mineapolis: University of Minnesota Press, p 23.

Schiller, Friedrich (1967) Letters on the Aesthetic Education of Man. (Trans.) and introduced by E.M. Wilkinson and L.A. Willoughby. 
